\title{
ARTICLE
}

\section{The common law defence of automatism: a quagmire for the psychiatrist}

\author{
Keith J. B. Rix
}

Keith Rix is an Honorary Consultant Forensic Psychiatrist in the Norfolk and Suffolk NHS Foundation Trust and Visiting Professor of Medical Jurisprudence, Institute of Medicine, University of Chester, where he is involved with the new MSc in Medicolegal Practice. He has recently been elected an Honorary Fellow of the Faculty of Forensic and Legal Medicine of the Royal College of Physicians.

Correspondence Professor Keith J.B. Rix, The Grange, 92 Whitcliffe Road, Cleckheaton BD19 3DR, UK. Email: keith@drkeithrix.co.uk

\section{SUMMARY}

This article sets out the complicated and confused law on automatism and identifies the role of the psychiatrist, including paradoxically a role in cases of non-psychiatric disorder where the law requires evidence from a doctor approved under section 12 of the Mental Health Act. Legal definitions of automatism are introduced. The internal/external distinction, evidential burden, burden of proof, standard of proof, prior fault, intoxication and the degree of impairment illustrate how the courts limit the defence. Detailed accounts are given of cases in which the defence of automatism has been based on psychiatric disorder and on the effects of psychotropic drugs. Suggestions are made for approaches to assessment and medicolegal reporting.

\section{LEARNING OBJECTIVES}

- Understand the role of the psychiatric expert in cases of suspected automatism

- Understand the law relating to the mental condition defence of automatism

- Know how to assess and report on cases of alleged automatism for the courts

\section{DECLARATION OF INTEREST}

None

A judge once referred to the law on automatism as a 'quagmire' ( $R$ v Quick [1973]). More recently, Lord Justice Davis referred to one aspect as 'illogical, little short of a disgrace and should be abolished' (Law Commission 2013: para 1.46). However, law reform is slow. Automatism is in a queue behind unfitness to plead. Even if reform proposals result in a bill, there need to be parliamentary will and time for it to be enacted.

In the meantime, psychiatrists are required even where the condition is non-psychiatric (Box 1). This is because conditions such as diabetes and epilepsy are regarded in law as 'internal' causes of automatism and raising the defence of 'insane automatism'. In such cases, the court requires evidence from at least one registered medical practitioner approved under section 12 of the Mental Health Act 1983.

\section{The law}

\section{The nature of the defence}

The automatism defence has no statutory basis; no Act of Parliament defines it, sets its limits and governs its application. It is a common law defence, depending on judicial decisions made over the years and in different jurisdictions. Different judges, dealing with quite dissimilar cases, have produced differing definitions (Box 2). There are

BOX 1 Conditions potentially giving rise to a defence of automatism

- Diabetes:

acute neuroglycopaenia

subacute neuroglycopaenia

hyperglycaemia

- Sleep disorders:

sleepwalking (somnambulism)

confusional arousal/sudden arousal disorders

sexsomnia (sexual behaviour in sleep)

obstructive sleep apnoea/hypopnoea syndrome

- Epilepsy

- Multiple sclerosis

- Ophthalmic migraine

- Cerebrovascular disease

- Cerebral tumour

- Cerebral oedema

- Concussion

- Psychiatric disorders: hysterical fugue personality disorder psychosis post-traumatic stress disorder

- Drug toxicity 
BOX 2 Legal definitions of automatism

- Action without conscious volition (Gresson P in $R v$ Cottle [1958])

- Action without any knowledge of acting, or acting with no consciousness of what is being done (Gresson $\mathrm{P}$ in Cottle)

- An involuntary movement of the body or limbs of a person following complete destruction of voluntary control (Watmore v Jenkins [1962])

- An act which is done by the muscles without any control by the mind, such as a spasm, a reflex or a convulsion; or an act done by a person who is not conscious of what he is doing (Denning LJ in Bratty $v$ A-G for Northern Ireland [1963])

- The state of a person who, though capable of action, is not conscious of what he is doing; this means unconscious, involuntary action, and it is a defence because the mind does not go with what is done (Viscount Kilmour LC in Bratty)

- Total alienation of reason amounting to a complete absence of self-control (Lord Hope in R v Ross (1991))

two particular features: the lack, or an altered state, of consciousness and the absence of volition.

\section{The internal/external distinction}

The internal/external distinction in automatism is particularly troublesome (Table 1). Where automatism results from an 'external' cause such as head injury, it is a 'non-insane (sane) automatism' (hereinafter 'sane automatism'). It is a complete defence. It results in acquittal. Where it is an 'internal' cause such as epilepsy, it is an 'insane automatism', it amounts to (legal) insanity and disposal is under section 24 of the Domestic Violence, Crime and Victims Act 2004 (the DVCA), which has amended the disposal options under the Criminal Procedure (Insanity and Unfitness to Plead) Act 1991 (the CP(IUP)A).

Various problems result. It is quite inconsistent with medical, if not public, thinking to categorise someone with diabetes, for example, as insane. The stigma of 'insanity' can be a disincentive to raising the defence. Outcomes can be illogical, if not nonsensical. Someone with diabetes who fails to take their insulin and, in a hyperglycaemic state, carries out what is alleged to be a criminal act is treated as insane. If they adhere to their insulin regime but fail to eat and, in a state of hypoglycaemia, carry out the same act they are acquitted. Internal and external factors can operate together. The jury have not only to consider their relative contributions, but to do so with reference to differences in relation to burden and standard of proof.

\section{The evidential burden, the burden of proof and the standard of proof}

Where the defence of automatism is raised, the judge has to decide first whether it has a proper evidential foundation ('the evidential burden'). If not, it cannot proceed.

If there is a proper evidential foundation, the judge has to decide whether it is insane or sane automatism. If it is insane automatism, the burden of proof ('the legal burden') rests on the defence to prove its case on a balance of probabilities (what is known by convention as 'the civil standard'). If it is sane automatism, the prosecution bears the legal burden of proving all the elements in the offence necessary to establish guilt and it has to do so to 'the criminal standard' of proof, which means 'beyond reasonable doubt' (Woolmington v DPP [1942]). This means that the prosecution must prove beyond reasonable doubt that there was a voluntary act that satisfied the actus reus requirement for the offence. This is a high hurdle for the prosecution. It is sufficient for the defence to raise no more than a doubt as to the defendant's guilt for the prosecution to be unable to prove its case beyond reasonable doubt.

Where there are issues of both insane and sane automatism, the judge has to distinguish them in summing up to the jury and remind them of the different burdens and standards of proof. It is a tall order for many jurors to make sense of this.

\section{Prior fault}

The defence may be difficult or rendered invalid where the accused was at fault in getting into such a condition.

It was withheld from a driver who fell asleep at the wheel, because he should have pulled over when he began to feel drowsy (Kay $v$ Butterworth (1945)), and from another who drove while

\section{TABLE 1 The current classification of automatisms}

\begin{tabular}{|c|c|c|c|}
\hline & Some accepted causes & Verdict & Outcome \\
\hline $\begin{array}{l}\text { Insane } \\
\text { automatism }\end{array}$ & $\begin{array}{l}\text { Epilepsy } \\
\text { Hyperglycaemia } \\
\text { Cerebral tumour } \\
\text { Multiple sclerosis } \\
\text { Sleepwalking } \\
\text { Arteriosclerosis } \\
\text { Hypoglycaemia }\end{array}$ & $\begin{array}{l}\text { Not guilty } \\
\text { by reason of } \\
\text { insanity (the } \\
\text { 'special verdict') }\end{array}$ & $\begin{array}{l}\text { Disposal under } \\
\text { the Domestic } \\
\text { Violence, Crime } \\
\text { and Victims Act } \\
2004\end{array}$ \\
\hline $\begin{array}{l}\text { Non-insane } \\
\text { (sane) } \\
\text { automatism }\end{array}$ & $\begin{array}{l}\text { Head injury } \\
\text { Anaesthetic } \\
\text { Sneezing } \\
\text { Post-traumatic stress disorder }\end{array}$ & Not guilty & Acquittal \\
\hline
\end{tabular}


sleepwalking after drinking alcohol, because he had previously experienced sleepwalking episodes after drinking (Finegan v Heywood (2000)). It failed where a driver suffered an acute hypoglycaemic episode: he should not have been driving because 3 months previously he had been involved in an accident when hypoglycaemic ( $R$ v Marison (1997)). Sentencing a driver with diabetes for causing death by dangerous driving, the judge said that 'monitoring of his condition and his blood sugar levels in particular were to put it mildly grossly mismanaged and grossly inadequate' (Law Commission 2013: p. 236, para. B.54).

Even a driver who has swerved in response to a wasp that has flown into their car may be at fault for not stopping to deal with the distraction.

There are, however, examples of successful reliance on states amounting to automatism notwithstanding prior fault. A driver with an insulinoma was stopped by police for a driving offence when hypoglycaemic but successfully relied on hypoglycaemia in the civil action that was brought after he crashed into a house later the same day (Mansfield $v$ Weetabix [1998]). When the judge heard evidence about a woman's insulindependent diabetes, he directed her acquittal of causing death by dangerous driving on the basis that she was not at fault ( $R v_{v}$ Gilbert [2006]). However, she had previously suffered three hypoglycaemic episodes which had come without warning and, although recommended to check her glucose level before driving, had not done so.

\section{Intoxication}

There is a general rule that self-induced intoxication, however caused, is not a defence to offences of basic intent or recklessness. This applies to automatism. A man who took LSD and killed his girlfriend in the belief that she was a snake had his conviction for manslaughter upheld because his automatism was self-induced ( $R$ v Lipman [1969]).

\section{Degree of impairment}

The rule is that there has to be a complete destruction of voluntary control. Impaired, reduced or partial control is not enough.

A driver with diabetes was, over the course of 5 miles, able to react to stimuli and take control of his limbs, albeit perhaps imperfectly; he drove at appropriate speeds, veered away from a vehicle, braked behind a stationary traffic queue and, although incoherent when someone opened his car door, restarted the engine, drove home and parked the car (Broome v Perkins (1987)). This was regarded as evidence that there was not a complete destruction of voluntary control and his conviction of driving without due care and attention was upheld.

The defence also failed where, following a collision, the driver's ability to circumvent a police road block was regarded as evidence of responding to his surroundings and being in full voluntary control ( $R$ v Isitt (1978)).

This rule is applied inconsistently. In sleepwalking cases, the ability to start a car engine does not seem to raise an issue as to the extent to which the mind controls the body. The defence was successful where a sleepwalking defendant started the engine to drive to the police station having already driven several miles, through seven sets of traffic lights, to his in-laws, where he killed his mother-in-law and attempted to kill his fatherin-law ( $R$ v Parks (1992)).

\section{Psychiatric conditions potentially giving rise to a defence of automatism}

\section{Sleep disorders}

The case in Box 3, described by Ebrahim \& Fenwick (2008), is illustrative of sleepwalking. This was held legally to be a case of insane automatism. The defendant was ordered to be detained in hospital (this being prior to the DVCA, because the offence charged was murder, a disposal of a hospital admission order with restrictions under the CP(IUP)A was the only disposal available to the court).

Box 4 illustrates a case of sexsomnia. Potential weaknesses here were that the defendant was not disoriented on waking, the complainant recalled a conversation indicative of a high level of cognitive functioning and the defendant had partial recall

BOX 3 Homicide in the course of sleepwalking

In the case of $R v$ Lowe (unreported), the defendant killed his father. The defendant had a personal and family history of sleepwalking. The attack probably started in his bedroom and continued downstairs, where a cupboard was pulled from the wall and a chair broken. His father was dragged through the hallway and out of the front door, where his head was banged on the pavement and against a car. The defendant took a shower, probably in his clothes, and made a very poor, disorganised attempt to mop up some blood with a towel. It was thought that the defendant's father was likely to have aroused the defendant from sleep either by a drunken attack or by shouting. Medical evidence was to the effect that the defendant had responded with a confusional episode and this had led to a sleepwalking episode. The defendant was ordered to be detained in hospital.

(Ebrahim 2008) 
of events. With evidence of both internal and external factors, the court recognised difficulties. The defence evidence was that there was (a) an established history of sexsomnia (internal), (b) something to induce a sleep disorder (external) and (c) proximity (external). As the external factors were sufficient evidence for sane automatism to be left to the jury, the judge's direction was that in order to convict they had to be sure that the defendant was not in an automatic state at the time of penetration. He was acquitted.

\section{Hysterical fugue}

In $R$ v Isitt (1978) it was asserted that the driver of a stolen vehicle was in a hysterical fugue so his subconscious mind was in control and therefore he would not have appreciated what he was doing. However, his ability to circumvent a police road block was regarded as evidence of being in full voluntary control. His defence failed. This is probably illustrative of the recommendation that 'the psychiatrist who deposes to dissociation in improbable circumstances should be subjected to skilled and deeply sceptical cross-examination, and [...] the Crown should, where possible, call counter-evidence' (Williams 1983).

\section{Personality disorder}

Box 5 concerns a man convicted of wounding with intent ( $R v$ Roach [2001]). The defence relied on two psychiatrists who were of the opinion that this was 'insane automatism of psychogenic type'. One diagnosed an antisocial personality disorder. His evidence was:

'Based on his childhood experiences and his lifelong relationship with his father, his recent conflict with his rather strong-willed partner and finally confrontation with a perceived humiliation from a fellow worker and specially under the mitigation of fatigue, alcohol and prescribed medication, the most likely diagnosis is obviously an insane automatism of psychogenic type'.

The other listed three contributory factors:

(1) Mixed Personality Disorder in the form of "an inclination to impulsivity, but an avoidance of violence (he tells me)";

(2) "A long-standing learnt sensitivity to humiliation from aggressive figures";

(3) Impairment [...] of his "higher mental functions" by a mixture of Carbamazepine [...] $200 \mathrm{mg}$ twice daily, Paroxetine [...] $20 \mathrm{mg}$ [...] daily, two large vodkas and fatigue. The appellant had had life stresses in his previous six months consisting of a deteriorating relationship with his partner with outbursts of verbal violence and violence to their property and the failure of his plan to become a single parent family, perceived as sabotaged by his parents, particularly his father. His 'immediate stressor' was feeling abused and

BOX 4 Sexsomnia as a defence against a charge of rape

The following example is based on an actual case, but details have been altered to protect the individual's anonymity.

The defendant had sexual intercourse with an intoxicated woman with whom he shared a bed following a family party. He was also intoxicated. His evidence was that he was woken and startled by her voice. He thought that she was getting up for the bathroom but she said something about contraception, in response to which he thought, 'What's going on?' and then turned over and went back to sleep until woken by a relative.

Her evidence was that she told the defendant to stop and there followed a dialogue which included the defendant asking her if he needed to use contraception, if she was taking an oral contraceptive and if she was free of sexually transmitted disease. When she asked him to stop and made the excuse that she needed to check on her sister, he apologised but asked whether he could perform cunnilingus.
There was evidence that the defendant had a cousin who walked in his sleep and that his brother had a history of sexsomnia. There was also evidence from the defendant's wife and his ex-wife of being woken to find that he was having sexual intercourse with them while he was asleep and with no recollection the following morning.

The defendant himself reported a number of apparent episodes of sleepwalking. He had woken in the bed in the spare room in his house. He had urinated in a wardrobe. He had been stopped from climbing over a balcony. His ex-wife's evidence was that the defendant sleepwalked at night, and the more so if he had consumed a lot of alcohol. Defence psychiatric evidence was to the effect that the alleged offence occurred in the course of sexsomnia. Alcohol and the proximity of the complainant were identified as external factors, and genetic factors and snoring were identified as internal factors.

The defendant was acquitted.

humiliated, ongoing for two days, by his (in his view) incompetent supervisor'.

The evidence of the prosecution's psychiatrist was that the amnesia, even if genuine, did not necessarily denote inability to form the required intent. He found no evidence that this was a psychogenic automatism and pointed out that, if the defendant had been in such a state, the man would have been bewildered following

\section{BOX 5 Personality disorder as a basis for a defence of automatism}

The case is that of $R v$ Roach [2001]. The incident involved two employees of a catering franchise working at the Royal Tournament. They disliked each other. After the complainant asked the defendant if by chance he had found his mop, the defendant exclaimed, 'You're not my supervisor'. The complainant told him to cool down and he walked off. As the complainant was packing up, the defendant put a serrated knife to his neck and said, 'See this knife, I'll cut your fucking throat with it'. The complainant retreated with the defendant following him, swearing all the time, 'Fucking frog bastard'. A witness heard him say, 'Don't take the fucking piss out of me' and he then saw the defendant repeatedly stab the complainant.
Immediately after the stabbing was over, the defendant was heard to say, 'Everything's cool, don't worry' and 'He's taken the piss, he's saying we're no good'. There was also evidence from an Army musician that the defendant stopped attacking the complainant because it appeared that he had a sudden realisation of what had happened and dropped the knife, that the defendant then approached the musician and other soldiers behaving as if nothing had happened and appearing unconcerned and that following the assault he appeared to 'snap out of something'. Another witness described the defendant laughing and joking following the assault as if nothing had happened. The defendant was convicted. 
arrest. His opinion was that the behaviour was entirely consistent with someone who had become increasingly anxious and lost his temper. The defendant was convicted.

It was a ground for appeal that, in his summing up, the judge had failed to draw attention to the evidence of two witnesses which provided some ambivalent support for the case that the appellant had not realised what he was doing. This was accepted and, also for other reasons, the Court of Appeal concluded that the conviction was unsafe and quashed it. This conclusion was reached with some reluctance, as it seemed to the Court that the case against the appellant was strong and that the jury had almost certainly rejected the defence on the basis of a strong preference for the prosecution psychiatrist's assessment and evidence.

\section{Psychosis}

In the case of $R v$ Coley [2013], where Mr Coley was convicted of attempted murder carried out after consuming a great deal of cannabis and suffering a 'brief psychotic episode', the Court of Appeal upheld the trial judge's decision not to allow the defence of automatism. However, it thought that there was an issue as to whether the appellant had been acting consciously. It accepted that his mind may well have been affected by delusions or hallucinations 'and in that sense his detachment from reality might be described by some as an absence of conscious action', but it went on to hold that such a condition 'clearly falls short of involuntary' and observed:

'He must have made the decision to dress specifically for his intrusion next door, and to arm himself with his knife. He made the decision to find the keys and let himself in. That was not, as it seems to us, capable of being described as involuntary action'.

\section{Stress and post-traumatic stress disorder}

Although 'stress' is obviously an external factor, the courts have not allowed it to found a defence of sane automatism because 'the ordinary stresses and disappointments of life which are the common lot of mankind do not constitute an external cause' ( $R$ v Rabey [1980]). As they do not make everyone behave like an automaton, the fact that someone has done so is regarded as evidence that the real cause of the behaviour lies in their make-up, it is internal, an insane automatism.

Box 6 is a case in which post-traumatic stress disorder (PTSD) resulting from rape was relied on as the basis for an automatism defence, but the defendant was found guilty ( $R v$ Tate $[1990])$. This is not surprising. Following her victims, opening the penknife blade and demanding the second victim's handbag suggest that her mind went with her actions. However, it is an important case as it has established that because rape cannot be regarded as one of the 'ordinary stresses of life' and 'such an incident could have an appalling effect on any young woman, however well-balanced normally', the defence raised is not one of insane automatism resulting from a disease of the mind, i.e. PTSD, but sane automatism resulting from a malfunctioning of the mind due to an external factor, i.e. rape.

\section{Drug toxicity as a cause of automatism}

In $R$ v Ball [2007], an off-duty police officer was alleged to have caused danger to road users by interfering with traffic equipment. He was being treated with antidepressants and hypnotics. A psychiatrist initially expressed the opinion that his 'account was compatible with a period of automatic behaviour with no memory of events [and] said that the taking of the sleeping pill with alcohol would be likely to cause a blackout and cause somebody to behave as an automaton'. When a second doctor refuted this, asserting that his behaviour 'suggested the results of alcohol exaggerated by the sleeping tablet rather than automatism', the psychiatrist agreed with him. The defence was then abandoned in favour of a guilty plea.

Citalopram was implicated in $R v$ Smallshire [2008]. The appellant had been convicted of causing grievous bodily harm with intent. He told the police that he 'just went absolutely berserk', made a 'split second decision' to arm himself with

BOX 6 Post-traumatic stress disorder as the basis of a defence of automatism

The case is $R v$ Tate [1990]. Three days after being raped, the defendant and two others took part in a robbery and she was also charged with assault occasioning actual bodily harm. She claimed that she had post-traumatic stress disorder as a result of being raped and had acted in a dream-like state. When first seen, the defendant was standing by the victim's car saying, 'I'm ill, I'm ill'. There was evidence, however, that following the robbery of the first of the two victims, she had followed the two victims and another woman to a car, stabbed this third woman in the stomach with a penknife when she was asked what she was doing and why and had then pushed past her, leaned into the car and demanded the second victim's handbag. The judge ruled that if it was a state of automatism it was sane automatism and allowed her defence to go to the jury. It was part of the prosecution case that the opening of the blade of the penknife required a controlled and positive action by the defendant and so there was partial control. She was convicted. 
a knife and decided he had to 'get the upper hand' and 'get the situation under control'. This was not accepted as automatism.

Temazepam was implicated in McGhee $v R$ [2013]. It was an incident at an off-licence that resulted in convictions for assault occasioning actual bodily harm and wounding with intent. The appellant said that he had taken temazepam for tinnitus and then drunk alcohol, contrary to the warning on the medication bottle. He appealed because the trial judge refused to allow automatism to go to the jury. A psychiatrist gave evidence that the appellant was clearly aware, and in control, of his actions even if his judgement was impaired. A psychopharmacologist said that the combined effects of alcohol and temazepam might have resulted in paradoxical disinhibition. There was videotape evidence of his 'clearly voluntary behaviour in the shop and outside over quite an extended period'. The Court of Appeal ruled, 'Disinhibition is exactly not automatism'.

\section{An approach to the assessment of possible automatism}

Assessment should be informed by familiarity with any medical condition diagnosed or suggested. A refresher with textbooks of postgraduate medicine and organic psychiatry should assist.

\section{History}

Enquiry may reveal a family history of a relevant condition, for example a family history of sleepwalking or, in cases of sexsomnia, of arousal disorders. The judge will assist the jury as to the weight to be attached to such a history.

Enquire as to previous psychiatric history. Major depressive disorder, obsessive-compulsive disorder (Ohayon 2012) and alcohol misuse/ dependence (Moldofsky 1995; Ebrahim 2012; Ohayon 2012) increase the risk of sleepwalking. There is an association between sleep apnoea and depression (Ohayon 2003).

A history of mild sleep disordered breathing (snoring) or sleep apnoea is important, as these are the most commonly identified triggers for sleepwalking. There is an association between sleep apnoea syndrome and sexsomnia (Ohayon 2012). Excessive daytime sleeping may be a pointer to sleep apnoea/hypopnoea syndrome.

Enquire as to drug use, which is a recognised trigger for sleepwalking (Moldofsky 1995; Ohayon 2012). Enquire as to alcohol use. The finding that a minority of patients report an association between alcohol and sleepwalking (Lopez 2013) confirms the generally held view of some experts (e.g. Ebrahim 2009, 2012) that there is a positive association between alcohol and sleepwalking, but other experts disagree strongly (e.g. Pressman 2009). Furthermore, it should be noted that the International Classification of Sleep Disorders (American Academy of Sleep Medicine 2014: p. 237) states that:

'Disorders of arousal should not be diagnosed in the presence of alcohol intoxication. The behaviour of the alcohol-intoxicated individual may superficially resemble that of the sleepwalker. However, the sleepwalker is typically severely cognitively impaired, but with only limited motor impairment. The alcohol-intoxicated individual's level of cognitive functioning may be reduced, but not absent, whereas motor behaviour is often severely impaired'.

However, this prohibition as to diagnosis is not universally accepted. For example, Rumbold et al (2014) state:

'There are certainly good grounds for scepticism when an individual who is heavily intoxicated claims to have been sleepwalking, but current evidence does not support the preclusion of all alcoholrelated sleepwalking in clinical or forensic settings'.

That this is such a controversial area is an indication that in cases of what appears to be sleep disorder, most psychiatrists are likely, indeed advised, to recommend the further instruction of one of the UK's very few sleep disorder experts.

Stress, strong emotions, sleep deprivation, alcohol and intense physical activity have been identified as triggers for increasing the frequency and severity of sleepwalking episodes in non-rapid eye movement (non-REM) sleep arousal disorders (Lopez 2013).

Enquire whether the accused has previously experienced symptoms the same as, or similar to, those experienced at the material time. In a sleepwalking case, a childhood history of sleepwalking will be highly relevant. This is common in adult sleepwalkers. Onset is less common in adolescence and uncommon in adulthood. Lopez et al (2013) found that $17 \%$ of adult sleepwalkers had onset as an adult. However, it can occur following a head injury or febrile illness or as a side-effect of medication, particularly antidepressants, major tranquillisers and minor tranquillisers. In sexsomnia there is usually a history of sleep disorders. Such a history needs to be brought to the attention of the court so that it can decide whether this amounts to prior fault.

Obtain an account of the accused's history just before and at the material time. The accused may report nothing unusual prior to a period of apparent amnesia that includes the material events. Their account may include a report of potentially significant symptoms prior to a period of apparent amnesia for the material events. Their 
account may include a recollection of events that occurred at the material time.

This account may usefully start with what had happened from the beginning of the day. Sometimes there is a longer relevant history, as stressful life events, fatigue and sleep deprivation can trigger sleepwalking. Excess alcohol, too little sleep and stress are recognised triggers for sexsomnia (Moldofsky 1995). An incident in the early hours of the morning or early afternoon can suggest obstructive sleep apnoea/hypopnoea.

In someone with a history of diabetes, find out whether they checked their blood glucose and, if it was low, whether they ate some food. Enquire as to physical exertion. Someone with established diabetes might be expected to know that a particular level of exercise would make them vulnerable to hypoglycaemia.

Where an accused person reports such symptoms as profuse sweating, rapid heart beat and tremor and has a history of, or has been subsequently diagnosed with, diabetes, this may be consistent with acute hypoglycaemia. Failure to respond appropriately to premonitory symptoms can rule out the defence. Likewise, for a driver, failure to pull over in response to a partial loss of control can raise an issue of prior fault.

The last recollection prior to the incident can be critical. Box 7 is the case of a lorry driver charged with causing death by dangerous driving. His last recollection of experiencing something 'like a

BOX 7 Occipital lobe seizure causing an accident

The following example is based on an actual case, but details have been altered to protect the individual's anonymity.

A lorry driver was charged with causing death by dangerous driving. He described experiencing something 'like a welder's arc flash' and remembered nothing more until someone asked him to get out of his cab. Witnesses observed the lorry being driven erratically: repeated alternating between left and right indicators, unusual braking at traffic lights, a slow reaction to a green light and revving of the engine without increasing speed. The driver looked 'phased out'; he was staring and looking aimlessly forward. There was expert neurological evidence that he had suffered an occipital lobe seizure which started in the left occipital lobe, took around $30-60$ s to spread to the other occipital lobe, spread to the visual cortices, causing a loss of vision in the right visual field, consistent with driving across the middle of the road to the right, and then a loss of awareness. The expert psychiatric evidence was that the driver was in a state of insane automatism. welder's arc flash' was relied on as evidence that he had suffered an occipital lobe seizure.

An accused person may recall nothing abnormal prior to a period of apparent amnesia for the material time but have a history of diabetes, including a history of what may be subacute neuroglycopaenia or hypoglycaemic unawareness, and therefore a history of episodes in which there is no awareness of the usual premonitory warning signs of acute neuroglycopaenia. Previously unrecognised hypoglycaemic unawareness is very rare so, where it is raised as a defence, it is highly likely that the defence will fall foul of the prior fault principle.

What does the accused recall of the material events? Complete amnesia is usual. This is to be expected if there is unconsciousness. Some partial recollection may be consistent with automatism if there has been an impairment of voluntary control of actions. There may be some fragments of distorted memory in cases of sleepwalking.

What are the first memories following the episode? Usually, mentation on waking from sleepwalking is of non-narrative and non-dreamlike experiences with only a vague visual content and consisting mostly of thoughts and feelings (Ebrahim 2008). There may be disorientation or bewilderment.

\section{Examination}

The nature and extent of physical examination will depend on the medical condition at issue and any physical examination already carried out by more appropriately qualified experts.

Mental state examination may be normal. Abnormal mental state findings may be relied on in support of psychiatric diagnosis, but are unlikely to assist as to mental state at the time of the alleged automatism.

\section{Investigations}

Obtain the accused's medical records. They will assist in verifying, establishing or perhaps even refuting the accused's reported medical history. Of particular assistance are medical records relating to the time of the alleged offence.

There may be blood glucose measurements made soon after the incident. In a case of causing death by careless driving (HM Advocate $v$ Aitken (2012)), the defence was put on the basis that the accused had started a very low calorie diet the previous day. However, not only was there evidence that hypoglycaemia does not occur within 2 days of starting a low calorie diet, or even starvation, but the accused had a normal blood glucose when subsequently admitted to hospital. 
Investigations can also include study of witness statements, particularly eyewitnesses, CCTV recordings, police custody and interview records (especially where arrest has taken place soon after the material events), the police accident report and any independent accident investigation report.

Look for eyewitness accounts of the person's conversation and behaviour. A defence of automatism will be hard to advance if the person speaks and behaves as would be expected in someone who is not in an abnormal mental state.

In the 20-30 min following a concussive head injury there may be thrashing or flailing of limbs in a non-directed manner, uncooperativeness, wild swinging of the limbs in response to confrontation or attempted restraint, and aimless wandering (McCrory 2001). The accused may refuse to get on a stretcher or try to get out of an ambulance.

Eyewitnesses may report that the accused said that they were hungry, appeared anxious or pallid, were sweating or tremulous. They may describe the accused as looking and acting as though intoxicated, appearing bewildered, seeming to be in shock, acting like a robot or automaton, wandering aimlessly or lacking appropriate facial expressions. They may use terms such as 'paranoid', 'fidgety' and 'out of it' or say that the accused's eyes were not working normally. Or they may describe the accused responding appropriately to what they see or hear.

In the case of sudden arousal disorders or confusional arousal, only the evidence of eyewitnesses may establish the four diagnostic features:

- asleep long enough to reach deep sleep

- a stimulus sufficient to induce waking

- onset of abnormal behaviour immediately on waking

- the episode lasting for just a few minutes, although it can be longer in sleepwalkers and if there is alcohol intoxication.

There may be evidence supporting a posttraumatic amnesia. A statement from a witness may include details of a conversation with the person, whereas evidence from later witnesses indicates that the person has no recollection of the matters discussed.

Pay attention to the reported behaviour of the accused after the alleged offence. Is it that of someone with little or no recollection of what has just happened?

\section{The medicolegal report}

Where a non-psychiatric condition has been identified as a potential cause of automatism, the defendant's solicitors will usually have obtained a report from an appropriate specialist. They will then seek a report from a section 12 approved doctor. Although they ride 'piggy-back' on the other medical practitioner, the psychiatrist should not just 'rubber stamp' the first medical practitioner's opinion. They should look carefully at their opinion and how it has been reached.

Readers are referred elsewhere for a more detailed account of the law relating to, and the investigation by the appropriate specialists of, non-psychiatric disorders capable of founding a defence of automatism (Rix 2015). For example, in order to consider hypoglycaemic unawareness, investigations should include continuous glucose monitoring to examine the relationship between hypoglycaemia and reported symptoms. There was evidence in $R_{V}$ Clarke (unreported) (see Rumbold 2011) that Mr Clarke had experienced 26 episodes of biochemical hypoglycaemia but was aware of only two.

In the case of a possible sleep disorder, the role for most psychiatrists will be to provide a report that is sufficiently clear and detailed for the instructing solicitors to make out a case for a second report from a sleep disorder expert.

If the first expert appears to have overlooked evidence that calls their opinion into question, this should be raised in a preliminary draft report. In any event, the psychiatrist's report should include a statement to the effect that, insofar as there is evidence that falls outside their psychiatric expertise, they defer to the appropriate non-psychiatric experts.

Where the defence proceeds, the prosecution may obtain its own psychiatric evidence. The prosecution psychiatrist's role is no different from that of the psychiatrist instructed by the defence.

\section{Conclusions}

Automatism is a difficult area of the law but, whether instructed by defence or prosecution, the role of the psychiatrist is to apply their expertise and do their best to assist the delivery of justice.

\section{References}

American Academy of Sleep Medicine (2014) International Classification of Sleep Disorders: Third Edition (ICSD-3). AASM.

Ebrahim 10, Fenwick P (2008) Sleep-related automatism and the law. Medicine, Science and the Law, 48: 124-36.

Ebrahim 10, Fenwick P (2009) Sleep-related automatism and the law: response to Pressman et al. Medicine, Science and the Law, 49: 144-9.

Ebrahim 10, Fenwick P (2012) Sleep related violence, alcohol and sleepwalking. Brain, 135: 1-2.

Law Commission (2013) Criminal Liability: Insanity and Automatism. A Discussion Paper. Law Commission.

Lopez R, Jaussent I, Scholz S, et al (2013) Functional impairment in adult sleepwalkers: a case control study. Sleep, 36: 345-51.
MCO answers

$\begin{array}{lllll}1 \mathrm{a} & 2 \mathrm{c} & 3 \mathrm{~d} & 4 \mathrm{e} & 5 \mathrm{c}\end{array}$ 
McCrory P (2001) The medicolegal aspects of automatism in mild head injury. Journal of Sports Medicine, 35: 288-90.

Moldofsky H, Gilbet R, Lue FA, et al (1995) Sleep related violence. Sleep, 18: $731-9$

Ohayon MM (2003) The effects of breathing-related sleep disorders on mood disturbances in the general population. Journal of Clinical Psychiatry, 64: 1195-200.

Ohayon MM, Mahowald MW, Dauvilliers Y, et al (2012) Prevalence and comorbidity of nocturnal wandering in the US adult general population. Neurology, 78: 1583-9.

Pressman MR, Mahowald MW, Schenck CH, et al (2009) Sleep-related automatism and the law. Medicine, Science and the Law, 49: 139-43.

Rix KJB (2015) Automatism - wading through the quagmire. In Current Practice in Forensic Medicine (2nd edn) (eds J Gall, J Payne-James): in press. Wiley.

Rumbold J, Wasik M (2011) Case comment: diabetic drivers, hypoglycaemic unawareness, and automatism. Criminal Law Review, 11: $863-72$.

Rumbold J, Riha RL, Morrison I (2014) Alcohol and non-rapid eye movement parasomnias: where is the evidence? Journal of Clinical Sleep Medicine, 10: 345.

Williams G (1983) Textbook of Criminal Law(2nd edn). Stevens \& Sons.

\section{Cases}

Bratty v A-G for Northern Ireland [1963] AC 386.

Broome v Perkins (1987) 85 Cr App R 321.

Finegan v Heywood (2000) SLT 905, JC 444.
HM Advocate v Aitken (2012) GWD 2-20.

Kay v Butterworth (1945) TLR 61: 451.

Mansfield v Weetabix [1998] 1 WLR 1263.

McGhee $v R$ [2013] EWCA Crim 223.

$R v$ Ball [2007] EWCA Crim 3099.

$R$ v Clarke (unreported).

$R$ v Coley [2013] EWCA 223.

$R v$ Cottle [1958] NZLR 999.

$R v$ Gilbert [2006] EWCA Crim 3276.

$R$ v lsitt (1978) 67 Cr App R 44.

$R v$ Lipman [1969] 3 All ER 410.

R v Ouick [1973] OB 910, (1973) 57 Cr App R 722.

$R$ v Lowe (Manchester Crown Court 2005, unreported).

$R v$ Marison (1997) RTR 457.

$R$ v Parks (1992) $95 \mathrm{DLR}$ (4th) 27.

$R v$ Rabey [1980] SCR 513.

$R v$ Roach [2001] EWCA Crim 2698.

$R v$ Ross (1991) JC 210.

$R v$ Smallshire [2008] EWCA Crim 3217.

$R$ v Tate [1990] Crim LR 256.

Watmore v Jenkins [1962] 2 OB 572

Woolmington v DPP [1942] AC 1

\section{MCOs}

Select the single best option for each question stem

\section{Where the defence of insane automatism is raised, the court must receive evidence from:}

a one registered medical practitioner approved under section 12 of the Mental Health Act 1983

b two registered medical practitioners approved under section 12 of the Mental Health Act 1983

c a medical practitioner on the Specialist Register of the General Medical Council

d any two registered medical practitioners

e a Member or Fellow of the Royal College of Psychiatrists.

2 Which of the following has been recognised as a cause of 'sane automatism'?

a arteriosclerosis

b epilepsy

c post-traumatic stress disorder

d multiple sclerosis

e cerebral tumour.
3 To successfully argue the defence of sane automatism:

a the defence has to prove its case on the balance of probabilities

b the defence has to prove its case beyond reasonable doubt

c the defence has to comply with the M'Naghten rules

d the prosecution must fail to prove its case beyond reasonable doubt

e there has to be a complete destruction of voluntary control.

4 A defence of automatism will not succeed:

a in the event that there was something less than a complete destruction of voluntary control

$b$ in the event of prior fault

c unless the cause is external

d unless there is complete amnesia for the material events

e if it was self-induced.
5 In the assessment by a psychiatrist of a case of possible automatism:

a family history is irrelevant

b blood glucose should be measured

c mental state examination may be normal

$d$ physical examination is essential

e the accused's own recollections are of little assistance. 